\title{
Changes in saliva analytes in equine acute abdominal disease: a sialochemistry approach
}

\author{
María Dolores Contreras-Aguilar ${ }^{1}$, Damián Escribano ${ }^{1,2}$, Silvia Martínez-Subiela ${ }^{1}$, María Martín-Cuervo ${ }^{3}$, Elsa Lamy ${ }^{4}$, \\ Fernando Tecles ${ }^{1 *}$ (I) and Jose Joaquín Cerón ${ }^{1}$
}

\begin{abstract}
Background: The biochemical components of saliva can change in certain pathologies in horses, for example in acute abdominal disease. The aim of this study was (1) to evaluate if a panel of biochemical analytes usually used in serum can be measured in saliva of horses and (2) to study the possible changes of these biochemical analytes in saliva of horses affected by acute abdominal disease. A panel of 23 analytes was analytically validated in saliva of horses and possible changes in these analytes in a pilot study with six healthy horses and six horses with acute abdominal disease were evaluated. The analytes with significant changes were then evaluated in a larger population of 20 healthy and 37 diseased horses.

Results: Seven analytes showed significant increases in the pilot study which were confirmed in the larger population. The analytes which showed significant changes, and their median fold increase and significance shown in the larger population were salivary $\gamma$-glutamyl transferase (gGT, 2.3 fold, $P=0.001$ ), creatine kinase (CK, 6.2 fold, $P<0.001)$, urea (2.3 fold, $P=0.001)$, total bilirubin $(2.6$ fold,

$P<0.001)$, total proteins (3.2 fold, $P<0.001$ ), phosphorus $(P, 4.5$ fold, $P<0.001)$ and alpha-amylase (sAA, 8.5 fold,

$P<0.001)$. Total proteins, $P$ and SAA showed sensitivities higher than $70 \%$ at their optimal cut-off points and a specificity of $100 \%$ in differentiating between healthy horses and those with acute abdominal disease.

Conclusions: A panel of 23 biochemical analytes can be measured in saliva of horses, where gGT, CK, urea, total bilirubin, total protein, $\mathrm{P}$ and sAA levels are raised in horses with acute abdominal disease.
\end{abstract}

Keywords: Biomarkers, Colic, Horse, Saliva, Sialochemistry

\section{Background}

Saliva mainly consists of water, which represents up to 99\% of its total volume. In addition, studies on human and veterinary species have reported that saliva also contains compounds such as phosphorus (P), lactate, cholesterol, fatty acids, glucose, hormones such as cortisol, triglycerides, urea and uric acid $[1,2]$. In addition, saliva has enzymes such as salivary alphaamylase (sAA), lipase, carbonic anhydrase, adenosine deaminase (ADA), aspartate aminotransferase (AST), alanine aminotransferase (ALT), alkaline phosphatase

\footnotetext{
* Correspondence: ftecles@um.es

${ }^{1}$ Interdisciplinary Laboratory of Clinical Analysis (Interlab-UMU), Veterinary

School, Campus of Excellence Mare Nostrum, University of Murcia, Campus

de Espinardo s/n, 30100 Espinardo, Murcia, Spain

Full list of author information is available at the end of the article
}

(ALP), lactate dehydrogenase (LDH) and creatine kinase (CK), among others [3-8].

The composition of saliva can be affected by systemic disorders [9]. Due to this, there has been increased interest over recent years in the use of saliva as a diagnostic fluid. In addition, saliva has some advantages over blood since it is easily collected by non-invasive, non-stressful procedures $[10,11]$ and by non-trained personnel with a minimum of material. For these reasons, a new term in human medicine, "sialochemistry", has been created, which consists of the measurement of analytes included in the routine serum biochemistry profiles in saliva $[12,13]$. In animal species, saliva analytes have been studied in different situations. For example, total esterase (TEA), cholinesterase (ChE) and ADA increase in pigs affected by an acute stress or by a

(c) The Author(s). 2019 Open Access This article is distributed under the terms of the Creative Commons Attribution 4.0 International License (http://creativecommons.org/licenses/by/4.0/), which permits unrestricted use, distribution, and reproduction in any medium, provided you give appropriate credit to the original author(s) and the source, provide a link to the Creative Commons license, and indicate if changes were made. The Creative Commons Public Domain Dedication waiver (http://creativecommons.org/publicdomain/zero/1.0/) applies to the data made available in this article, unless otherwise stated. 
pathologic condition such as lameness [4, 5]. In horses, sAA and cortisol increase in acute abdominal disease, acting as possible pain-induced stress biomarkers [3]. In addition, in a proteomic study [14], acute phase proteins in saliva were observed to change in horses with this disease. However, to the authors' knowledge, other routine biochemistry analytes have not been measured in saliva in horses with acute abdominal disease, so their potential utility as biomarkers is unknown.

The objective of this paper was to evaluate if a panel of biochemical analytes usually used in serum can be measured in saliva of horses, and also to study the possible changes of these biochemical analytes in saliva of horses affected by acute abdominal disease. For this purpose, a pilot exploratory evaluation was first made of healthy horses and those with acute abdominal disease to assess possible differences between the two groups of animals in a profile of 23 biochemical analytes. Then, those salivary analytes that significantly varied in the pilot study were later clinically validated in a larger population.

\section{Methods}

\section{Pilot exploratory study}

The diseased population $(n=6)$, diagnosed as having acute gastrointestinal disease, came from the Veterinary Teaching Hospital of the University of Extremadura (Table 1). The diagnosis was based on history, physical examination, haematology and plasma biochemistry (Olympus Diagnostica GmbH AU 600, Beckman Coulter, Ennis, Ireland), transabdominal ultrasonography, and response to treatment by a board-certified internist $(\mathrm{MMC})$. In horses undergoing surgery, the diagnosis of the acute gastrointestinal disease was based on laparotomy findings.
The healthy population $(n=6)$ was composed of horses admitted for castration or routine health check in the Veterinary Teaching Hospital of the University of Extremadura and of privately owned horses from a stable in the province of Almería (Spain) (Table 1). The healthy horses showed no clinical signs of abdominal pain [15] during the physical examination. In addition, the heart rate (HR) and respiratory rate (RR) were within normal limits and they had no haematological or biochemical abnormalities.

\section{Confirmatory study}

The diseased population $(n=37)$, diagnosed as having acute gastrointestinal disease, came from the Veterinary Teaching Hospital of the University of Extremadura between January and October 2018. It was composed of 14 geldings, 14 stallions and 9 mares with $9 \pm 4.6$ years of age, including 12 Pure Spanish horses, 11 Crossbreds, 4 Warmbloods breeds, 4 Arabians, 3 Lusitanian horses, 2 Thoroughbreds, and 1 Friesian horse. The diagnosis was performed as in the pilot study and included enteritis $(n=8)$, strangulating lesion in the small intestine $(n=7)$, impaction of the pelvic flexure $(n=5)$, large colon displacement $(n=4)$, impaction of the right dorsal colon $(n=3)$, colitis $(n=3)$, large colon volvulus $(n=2)$, cecal tympany $(n=1)$, gastric perforation $(n=1)$, impaction of the small colon $(n=1)$, gastric ulcer syndrome $(n=1)$ and fecaloma in the small colon $(n=1)$.

The healthy population $(n=20)$ was selected as in the pilot study. It included 8 stallions, 6 females and 6 geldings, with an average age of $9 \pm 4.4$ years. The breeds included 14 Pure Spanish horses, 4 Crossbreds, 1 Arabian and 1 Thoroughbred.

\section{Sampling}

Saliva samples were obtained in the diseased population within 30 min of arrival at the hospital once horses were

Table 1 Overview of horses included in the pilot exploratory study

\begin{tabular}{|c|c|c|c|c|}
\hline Group & Age (year) & Gender & Breed & Diagnosis \\
\hline \multirow[t]{6}{*}{ Diseased horses } & 23 & Stallion & Pure Spanish horse & Enteritis \\
\hline & 4 & Mare & Crossbred & Impaction of the pelvic flexure \\
\hline & 8 & Stallion & Arabian & Impaction of the right dorsal colon \\
\hline & 5 & Stallion & Pure Spanish horse & Strangulated lesion in the small intestine \\
\hline & 10 & Mare & Crossbred & Fecaloma with ischemia \\
\hline & 7 & Gelding & Crossbred & Large colon displacement \\
\hline \multirow[t]{6}{*}{ Healthy horses } & 5 & Stallion & Pure Spanish horse & Healthy horse \\
\hline & 5 & Stallion & Pure Spanish horse & Healthy horse \\
\hline & 15 & Gelding & Pure Spanish horse & Healthy horse \\
\hline & 13 & Gelding & Crossbred & Healthy horse \\
\hline & 14 & Mare & Crossbred & Healthy horse \\
\hline & 4 & Mare & Pure Spanish horse & Healthy horse \\
\hline
\end{tabular}


in their box stalls. Upon arrival at the hospital, saliva samples were obtained prior to clinical examination or treatment. Saliva was collected by introducing a small sponge (Esponja Marina, La Griega E. Koronis, Madrid, Spain) into the horse's mouth toward the side of the cheeks, allowing the sponge to be chewed until it was soaked with saliva. The entire procedures took around 1 min. Then, sponge was placed in collection devices (Salivette, Sarstedt, Aktiengesellschaft \& Co, Nümbrecht, Germany) and was proceessed as previously reported [16]. Blood samples were collected just after saliva sampling by jugular venipuncture and transferred into lithium-heparin tubes ( $\mathrm{Li}$ Heparin, Aquisel ${ }^{\odot}$, Barcelona, Spain). Horses that yielded plasma samples with gross haemolysis and blood-contaminated saliva samples were excluded from the study. Horses with increased digital pulses or evident lameness were excluded in order to avoid clinical cases combined with laminitis or musculoskeletal problems (Additional file 1). Information about $\mathrm{HR}, \mathrm{RR}$ and rectal temperature were also obtained from the diseased and healthy populations.

\section{Plasma and saliva biochemistry profile}

The chemistry profile measured in plasma was integrated by:

- Enzymes: AST, ALP, $\gamma$-glutamyl transferase (gGT), lipase, amylase, LDH, CK, butyrilcholinesterase (BChE) and ADA.

- Metabolites: creatinine, urea, uric acid, total bilirubin, cholesterol, triglycerides, glucose and lactate.

- Proteins: total proteins, albumin, serum amyloid A (SAA) and Haptoblobin (Hp).

- Minerals: P and total calcium.

These assays were carried out on an automated chemistry analyser (Olympus Diagnostica $\mathrm{GmbH}$ AU 600), using commercial kits from Beckman (Beckman Coulter Inc., Fullerton, CA, USA) for all assays with the exception of ADA, which was measured with a Diazyme kit (ADA-D assay kit, Diazyme Laboratories, Poway, CA, USA), and BChE, which was measured according to a previously reported assay [17]. All these assays showed low inter and intra-assay imprecision $(<10 \%)$ and high linearity under dilution $\left(R^{2}>0.995\right)$ in serum.

The same chemistry profile, methods and apparatus were also used in saliva samples, with the exception of two analytes in which the analytical method was different: total proteins, which was evaluated using a commercial colorimetric kit to measure urine and LowComplexity Region (LCR) proteins (protein in urine and CSF, Spinreact, Spain), and BChE, which was measured following a previously described method [6]. In addition, two new analytes were measured in saliva samples: TEA activity, which was measured using a previously described method [5] in the Olympus chemistry analyser, and cortisol, which was analysed with a solid-phase competitive enzyme-amplified chemiluminescent immunoassay by the immunoassay system (Immulite 1000, Siemens Healthcare Diagnostic, Deerfields, IL) and validated in saliva by Escribano et al. [18]. The analytes in saliva were validated by the researchers' laboratory, showing an inter- and intra-variability lower than $10 \%$ of coefficient of variation $(\mathrm{CV})$ and were linear when applied to serial sample dilutions $\left(R^{2}=0.992 \pm 0.004\right)$ (Additional file 2). SAA and Hp could not be detected in saliva with the assays used in plasma (LZ SAA, Eiken Chemical Co.; and Haptoglobin turbidimetry, Spinreact, Spain, respectively). Therefore, they were excluded from the saliva evaluation. SAA and $\mathrm{Hp}$ assays used antihuman serum antibodies. The SAA assay used has been demonstrated to have cross-reactivity and adequate accuracy for SAA measurement in horses' plasma [19, 20], and the antibodies used in the assay for $\mathrm{Hp}$ measurement have cross-reactivity with plasma $\mathrm{Hp}$ in horse by western blot (data no showed), similarly to other human antibodies that showed cross-reactivity with $\mathrm{Hp}$ of horses [21].

\section{Severity scale}

The severity of the acute abdominal disease was assessed using the systemic inflammatory response syndrome (SIRS) score developed by Roy et al. [22], since it is easy to apply and because it has been demonstrated in a large population to be closely associated with the risk of death, mainly in cases of acute gastrointestinal illness cases. It was calculated as the sum of abnormal results in HR (> 52 beats/min), RR (> 20 breaths $/ \mathrm{min}$ ), white blood cell (WBC) count (above or below 5.0-12.5 $\times 10^{9} / \mathrm{L}$ ) and temperature (below or above $37.0-38.5^{\circ} \mathrm{C}$ ). Horses were considered to have SIRS when the score was equal to or higher than 2 (4-point-score).

\section{Statistical analysis}

To evaluate if there were significant differences in the analytes evaluated in saliva between the healthy and diseased populations in the pilot exploratory study, an unpaired Student's $t$ test (2-tailed) was performed. Previously, the values were transformed by log applying the formula $\ln x=\ln (x+1)$ [23], since all showed nonnormal distribution when checked using the ShapiroWilk test. The analytes that showed significant changes were studied in the confirmatory population using the statistical analysis described above. A stand-alone power program for statistical testing (G-Power) [24] was employed using the means and standard deviations of 
the selected analytes initially calculated in the pilot exploratory study, to establish the minimum number of individuals necessary to be included in the confirmatory study in each group for reaching a significance level of $\alpha=5 \%(P<0.05)$ and a power of $80 \%$. Additionally, a post hoc analysis was performed with the number of individuals used in the confirmatory study to guarantee that the significance level and power required were correctly obtained.

Spearman correlation was performed on the analytes of the confirmatory study, in order to evaluate a correlation between them in saliva and plasma, and between the SIRS score. An $r$ value from 0.90 to 1 was considered to have very high correlation, 0.70 to 0.90 high correlation, 0.50 to 0.70 moderate correlation, 0.30 to 0.50 low correlation and less than 0.30 little if any correlation [25]. A receiver operator characteristic (ROC) curve analysis was also performed to obtain the optimal cut-off point to maximise sensitivity and specificity for determining the healthy and diseased population with acute abdominal disease. All statistical analyses were performed using a spreadsheet (Excel 2000, Microsoft Corporation, Redmond, Washington, USA) and the commercial statistics package Graph Pad Prism 6 (GraphPad Software Inc., La Jolla, CA, USA). Values of $P \leq 0.05$ were selected to indicate significance in all analyses.

\section{Results}

\section{Differences in salivary analytes between diseased and} healthy populations

Medians and interquartile ranges (IQR) from all the analytes evaluated in the pilot exploratory study are shown in Table 2. There were seven analytes that showed a significant increase in horses with acute abdominal disease compared to healthy horses: gGT (showing a 1.8 difference between log means, 95\% confidence interval $[\mathrm{CI}] 0.6-3.0, P=0.008)$, CK (1.5 difference between log means, $95 \%$ CI $0.1-2.9, P=0.04)$, urea $(0.9$ difference between log means, 95\% CI 0.2-1.6, $P=0.02$ ), total bilirubin $(0.2$ difference between log means, $95 \%$ CI

Table 2 Medians, interquartile ranges (IQR, 25-75\%), minimal (Min) and maximal (Max) and values of a biochemical analysis performed in saliva from 6 healthy horses and 6 horses diagnosed with acute abdominal disease

\begin{tabular}{|c|c|c|c|c|c|c|c|c|}
\hline & Healthy & $(n=6$ & & & Diseasec & $\mathrm{s}(n=$ & & \\
\hline & Median & Min & $\operatorname{Max}$ & IQC & Median & Min & Max & IQC \\
\hline $\mathrm{AST}(\mathrm{IU} / \mathrm{L})$ & 101.8 & 45.5 & 205.8 & $47.8-146.3$ & 212.8 & 28.1 & 1216.9 & $68.5-615.7$ \\
\hline ALP (IU/L) & 58.5 & 1.0 & 79.8 & $30.3-74.4$ & 131.6 & 48.0 & 355.7 & 48.9-198.2 \\
\hline gGT (IU/L) & 31.1 & 2.5 & 62.8 & $19.3-51.8$ & $199.5^{* *}$ & 55.9 & 359.0 & $65.9-331.5$ \\
\hline Lipase (IU/L) & 49.8 & 10.0 & 100.1 & $13.23-75.3$ & 26.4 & 6.7 & 91.6 & $16.3-76.8$ \\
\hline LDH (IU/L) & 270.7 & 0.0 & 1195.0 & $41.9-662.3$ & 688.6 & 42.3 & 2896.0 & $43.9-1795.0$ \\
\hline CK (IU/L) & 11.1 & 0.0 & 23.5 & $2.4-15.4$ & $30.1^{*}$ & 7.0 & 140.7 & $13.5-88.9$ \\
\hline $\mathrm{BChE}(\mathrm{nmol} / \mathrm{mL} / \mathrm{min})$ & 19.2 & 5.6 & 31.1 & $12.1-27.5$ & 18.6 & 12.5 & 62.1 & $13.6-57.7$ \\
\hline ADA (IU/L) & 14.5 & 8.2 & 85.2 & $12.4-36.2$ & 41.1 & 11.8 & 216.3 & $26.9-111.6$ \\
\hline Creatinine $(\mu \mathrm{mol} / \mathrm{L})$ & 28.3 & 8.8 & 285.5 & $13.3-114.0$ & 33.6 & 0.9 & 106.1 & $3.5-64.53$ \\
\hline Urea (mmol/L) & 7.9 & 4.1 & 10.4 & $5.4-9.7$ & $18.8^{*}$ & 8.2 & 44.9 & $9.9-33.7$ \\
\hline Uric acid $(\mu \mathrm{mol} / \mathrm{L})$ & 59.5 & 51.8 & 103.5 & $52.3-86.8$ & 38.7 & 0.6 & 88.6 & $10.7-71.4$ \\
\hline Total bilirubin $(\mu \mathrm{mol} / \mathrm{L})$ & 2.9 & 1.0 & 10.3 & $1.7-6.2$ & $7.5^{*}$ & 3.6 & 13.5 & $4.3-10.4$ \\
\hline Cholesterol $(\mu \mathrm{mol} / \mathrm{L})$ & 35.4 & 0.00 & 249.8 & $0.0-169.7$ & 93.4 & 0.0 & 263.8 & $0.00-187.0$ \\
\hline Triglycerides (mmol/L) & 0.34 & 0.05 & 0.68 & $0.06-0.67$ & 0.21 & 0.02 & 3.64 & $0.04-1.17$ \\
\hline Glucose (mmol/L) & 0.54 & 0.01 & 1.80 & $0.13-1.05$ & 0.51 & 0.00 & 2.99 & $0.16-2.24$ \\
\hline Lactate $(\mathrm{mmol} / \mathrm{L})$ & 1.73 & 0.02 & 3.44 & $0.42-2.70$ & 0.39 & 0.01 & 20.91 & $0.09-9.32$ \\
\hline Total protein $(\mathrm{g} / \mathrm{L})$ & 1.65 & 0.96 & 4.23 & $1.01-2.72$ & $5.77^{* *}$ & 3.47 & 6.18 & $3.53-5.99$ \\
\hline Albumin (g/L) & 0.5 & 0.1 & 0.9 & $0.3-0.8$ & 0.8 & 0.1 & 2.6 & $0.4-1.5$ \\
\hline Phosphorus (mmol/L) & 0.26 & 0.04 & 0.48 & $0.12-0.34$ & $0.59^{*}$ & 1.20 & 2.04 & $0.24-1.72$ \\
\hline Calcium (mmol/L) & 4.7 & 4.2 & 7.0 & $4.2-7.0$ & 6.4 & 4.1 & 9.4 & $4.8-9.0$ \\
\hline sAA (IU/L) & 13.5 & 1.0 & 23.1 & $4.2-20.3$ & $109.3^{* *}$ & 43.7 & 544.3 & $51.7-446.5$ \\
\hline Cortisol $(\mu \mathrm{g} / \mathrm{dL})$ & 0.93 & 0.56 & 1.12 & $0.79-1.05$ & 0.91 & 0.6 & 1.08 & $0.60-1.02$ \\
\hline TEA (IU/L) & 141.7 & 77 & 165.5 & $120.7-159.4$ & 133 & 39.8 & 184.9 & $44.2-133.0$ \\
\hline
\end{tabular}

$A S T$ aspartate aminotransferase, $A L P$ alkaline phosphatase, $g G T$-glutamyl transferase, $L D H$ lactate dehydrogenase, $C K$ creatine kinase, $B C h E$ butyrilcholinesterase, $A D A$ adenosine deaminase, $S A A$ alpha-amylase salivary, TEA total esterase

Asterisk indicates statistically significant differences between groups $\left({ }^{*}: P<0.05 ;{ }^{* *}: P<0.01\right)$ 
$0.1-0.4, P=0.05)$, total protein (1.0 difference between log means, 95\% CI $0.4-1.6, P=0.004)$, P (0.6 difference between $\log$ means, 95\% CI $0.2-1.3, P=0.05$ ) and sAA (2.6 difference between log means, 95\% CI $1.3-3.8, P=0.001)$.

The power study calculated with the data from the pilot exploratory study showed that a minimum number of 11 healthy horses and 21 horses with acute abdominal disease would be needed to get appropriate results for the selected analytes. The post hoc analysis performed in the confirmatory study computed a power $96.4 \pm 0.1 \%$ for the gGT, CK, urea, total bilirubin, total protein, $\mathrm{P}$ and SAA results. When these analytes were evaluated in the study made in the larger population, horses with acute abdominal disease had values statistically higher than the healthy ones for all the analytes (Fig. 1).

The optimal cut-off point in saliva for predicting disease due to acute abdominal disease in the selected analytes was gGT $\geq 82.7 \mathrm{IU} / \mathrm{L} \quad(\mathrm{AUC}=0.79 ; \quad 95 \% \mathrm{CI}$ : $0.67-0.92$; sensitivity $70 \%$ [51-85]; specificity $80 \%$ [5694] $), \quad \mathrm{CK} \geq 30.1 \mathrm{IU} / \mathrm{L} \quad(\mathrm{AUC}=0.85 ; 95 \% \mathrm{CI}: \quad 0.74-0.95$; sensitivity 64\% [45-81]; specificity 100 [83-100]), urea $\geq 5.3 \mathrm{mmol} / \mathrm{L}(\mathrm{AUC}=0.79 ; 95 \% \mathrm{CI}$ : 0.67-0.92; sensitivity 66\% [46-82]; specificity 95\% [75-100]), total bilirubin $\geq 4.4 \mu \mathrm{mol} / \mathrm{L} \quad(\mathrm{AUC}=0.73 ; 95 \% \mathrm{CI}$ : 0.60-0.86; sensitivity $56 \%$ [38-72]; specificity 95\% [75-100]), total proteins $\geq 4.24 \mathrm{~g} / \mathrm{L} \quad(\mathrm{AUC}=0.95 ; 95 \% \mathrm{CI}$ : 0.90-1.01; sensitivity $77 \% \quad[60-90] ; \quad$ specificity $100 \%$ [83-100]), $\quad P \geq 0.50$ $\mathrm{mmol} / \mathrm{L} \quad(\mathrm{AUC}=0.94 ;$ 95\% CI: 0.89-1.00; sensitivity $75 \%$ [58-88]; specificity $100 \%$ [83-100]) and sAA $\geq$ $23.3 \mathrm{IU} / \mathrm{L} \quad(\mathrm{AUC}=0.92 ; 95 \% \mathrm{CI}$ : 0.86-1.00; sensitivity 73\% [56-86]; specificity 100\% [83-100]).

\section{Correlations}

The correlations between the different analytes selected in saliva, and between these analytes in saliva and plasma are shown in Table 3. High correlations in saliva were observed between gGT and urea $(\mathrm{r}=0.70, P<$ $0.001), C K$ and phosphorus $(r=0.71, P<0.001)$ and total proteins and $\mathrm{P}(\mathrm{r}=0.75, P<0.001)$. Moderate correlations in saliva were observed between gGT and total proteins $(\mathrm{r}=0.67, P<0.001), \mathrm{P}(\mathrm{r}=0.61, P<0.001)$ and CK $(\mathrm{r}=0.68, P<0.001)$; between $\mathrm{CK}$ and total proteins $(\mathrm{r}=0.69, P<0.001)$, urea $(\mathrm{r}=0.66, P<0.001)$, total bilirubin $(\mathrm{r}=0.57, P<0.001)$ and gGT $(\mathrm{r}=0.68, P<0.001)$; between urea and total proteins $(r=0.61, P<0.001)$ and $\mathrm{P}(\mathrm{r}=0.52, P<0.001)$; and between total proteins and sAA $(\mathrm{r}=0.61, P<0.001)$.

Positive correlations between saliva and plasma were observed in CK $(r=0.34, P=0.05)$, urea $(r=$ $0.49, P=0.002)$, total bilirubin $(r=0.37, P=0.02)$ and total proteins $(r=0.34, P=0.03)$. The SIRS score correlated in saliva with CK $(r=0.40, P=0.03)$, total bilirubin $(r=0.41, P=0.02)$, total proteins $(r=0.49$,
$P=0.003), \quad P(r=0.50, P=0.002)$ and $\mathrm{sAA}(r=0.35$, $P=0.05)$.

\section{Discussion}

This report describes for the first time that a profile integrated by various analytes that are used in routine serum biochemistry analysis can be measured in saliva in horses, and that some of these analytes can change in situations of acute abdominal disease.

In this report, we followed a similar approach that is made in proteomics studies when changes in a profile of proteins are studied in a clinical situation [26-28]. First, an exploratory study in a small population was performed in order to detect possible analytes that can change in the situation being studied, in our case acute abdominal disease. This population, as described in previous studies, comprised horses with different ages, sexes, and diagnoses in order to be representative of the different clinical conditions that can appear in this disease $[14,29]$. Then, the analytes showing changes were validated in a larger population.

Seven analytes were detected as being raised in saliva of horses with acute abdominal disease. Two of them were gGT and total bilirubin, which in serum are associated with liver dysfunction [30, 31]. Elevations in serum activity and concentration of both analytes have been associated with several causes of colic in horses, including cholelithiasis, infectious colitis, large colon displacement, ulcerative duodenitis, proximal enteritis and neoplasia [32]. Total bilirubin in saliva correlated moderately with plasma; therefore it could be postulated that part of the bilirubin that appears in saliva comes from plasma. In addition, total bilirubin was correlated moderately with the SIRS score, so it could be associated with the severity of the disease.

$\mathrm{CK}$, which in serum is associated with muscle damage [33], was raised in our study in the saliva of diseased horses. Increases in CK in saliva in situations of muscle damage have been described in dogs [34] and humans [7] and, therefore, the high values of CK in saliva of horses with acute abdominal disease could indicate the existence of muscle damage, which has been described as occurring in this disease by ischemic injuries $[35,36]$. One source of saliva CK could be the CK from plasma, since significant correlations were found between CK in plasma and saliva in our study, similarly to that reported in dogs [34]. In our study, CK in saliva had a significant although low correlation with SIRS status and therefore it could be an indicator of the severity of the process.

Increases in serum urea with normal values of creatinine are associated with reduced hydration status [37] or bleeding in the gastrointestinal tract [38]. Therefore, it could be postulated that similar causes could produce 

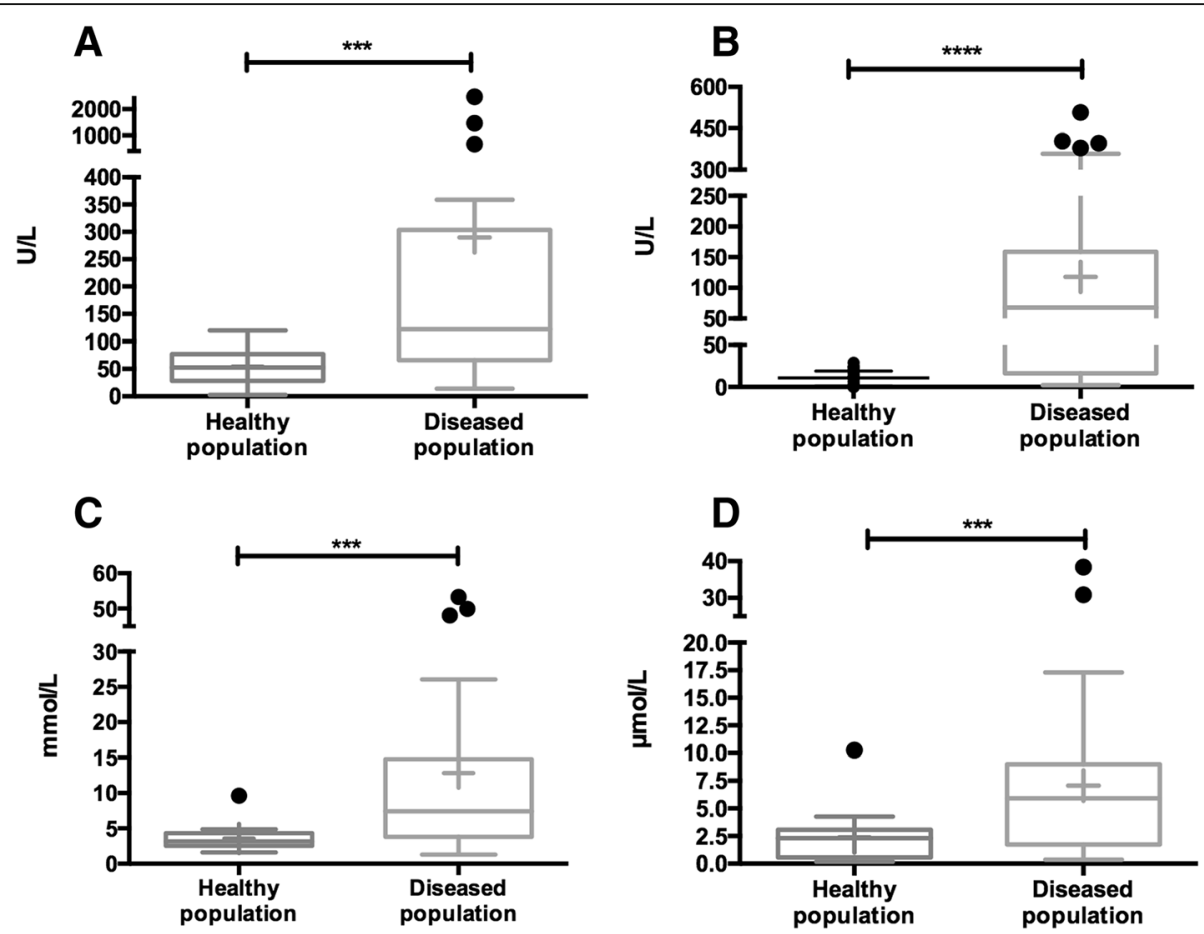

\section{$\mathbf{E}$}
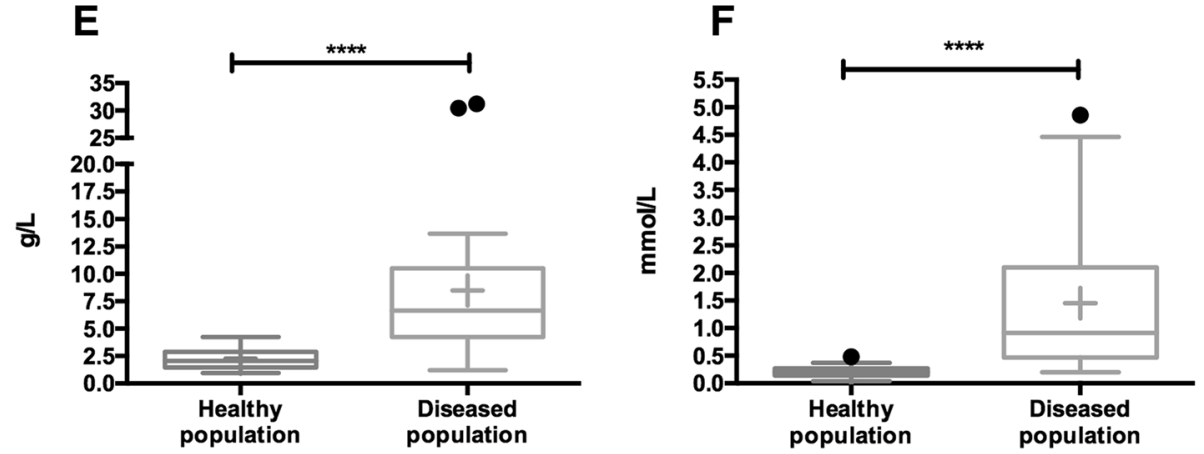

G

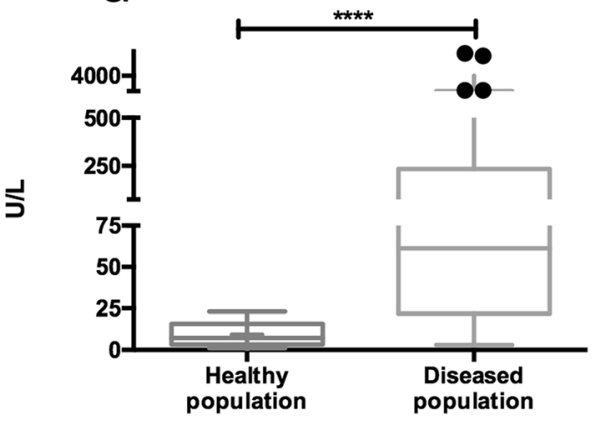

Fig. 1 Results of -glutamyl transferase (gGT) (a), creatine kinase (CK) (b), urea (c), total bilirubin (d), total protein (e), phosphorus (f) and salivary alpha-amylase (SAA) (g) in saliva of a healthy horses population $(n=20)$ and a diseased horses population $(n=37)$ with acute abdominal disease. The plot shows median (line within box), 25th-75th percentiles (box), 5th and 95th percentiles (whiskers) and outliers (•). The cross inside the box shows the mean. Asterisk indicates statistically significant differences between groups (**: $P<0.001 ; * * *: P<0.0001)$

the higher salivary urea found in our study in horses with acute abdominal disease. A moderate correlation between urea in saliva and plasma was observed. This correlation has also been reported in dogs with chronic kidney disease [39]. The higher concentration of total proteins observed in saliva in horses with acute 
Table 3 Spearman correlation coefficients between gGT, CK, urea, total bilirubin, total protein, phosphorus and sAA in saliva and plasma in healthy $(n=20)$ and diseased horses $(n=37)$ with acute abdominal disease

\begin{tabular}{|c|c|c|c|c|c|c|c|c|}
\hline & & Saliva & & & & & & \\
\hline & & gGT (IU/L) & CK (IU/L) & Urea (mmol/L) & Total bilirubin $(\mu \mathrm{mol} / \mathrm{L})$ & Total proteins (g/L) & Phosphorus (mmol/L) & sAA (IU/L) \\
\hline gGT & saliva & & $0.68^{* * *}$ & $0.70^{* * *}$ & 0.24 & $0.67^{* * *}$ & $0.61^{* * *}$ & 0.26 \\
\hline$(\mathrm{IU} / \mathrm{L})$ & plasma & 0.24 & 0.15 & 0.08 & 0.03 & $0.41 *$ & $0.36^{*}$ & 0.09 \\
\hline CK & saliva & $0.68^{* * *}$ & & $0.66^{* * *}$ & $0.57^{* * *}$ & $0.69^{* * *}$ & $0.71^{* * *}$ & $0.45^{* *}$ \\
\hline$(\mathrm{IU} / \mathrm{L})$ & plasma & 0.22 & $0.34^{*}$ & $0.36^{*}$ & 0.3 & 0.31 & $0.34^{*}$ & $0.55^{* * *}$ \\
\hline Urea & saliva & $0.70^{* * *}$ & $0.66^{* * *}$ & & $0.34^{*}$ & $0.61^{* * *}$ & $0.52^{* * *}$ & $0.37^{* *}$ \\
\hline$(\mathrm{mmol} / \mathrm{L})$ & plasma & 0.19 & 0.24 & $0.49 * *$ & $0.36^{*}$ & $0.35^{*}$ & 0.3 & 0.26 \\
\hline Total bilirubin & saliva & 0.24 & $0.57^{* * *}$ & $0.34 *$ & & $0.36^{* *}$ & $0.37^{* *}$ & $0.49^{* * *}$ \\
\hline$(\mu \mathrm{mol} / \mathrm{L})$ & plasma & 0.19 & 0.3 & 0.08 & $0.37^{*}$ & $0.51^{* * *}$ & $0.60 * * *$ & $0.39 *$ \\
\hline Total proteins & saliva & $0.67^{* * *}$ & $0.69^{* * *}$ & $0.61^{* * *}$ & $0.36^{* *}$ & & $0.75^{* * *}$ & $0.61^{* * *}$ \\
\hline$(g / L)$ & plasma & $0.32^{*}$ & $0.34^{*}$ & $0.35^{*}$ & 0.18 & $0.34^{*}$ & 0.29 & 0.26 \\
\hline Phosphorus & saliva & $0.61^{* * *}$ & $0.71^{* * *}$ & $0.52^{* * *}$ & $0.37^{* *}$ & $0.75^{* * *}$ & & $0.48^{* * *}$ \\
\hline$(\mathrm{mmol} / \mathrm{L})$ & plasma & 0.06 & -0.08 & 0.07 & -0.16 & 0.18 & 0.1 & 0.19 \\
\hline Amylase & saliva & 0.26 & $0.45^{* *}$ & $0.37^{* *}$ & $0.49^{* * *}$ & $0.61^{* * *}$ & $0.48^{* * *}$ & \\
\hline (IU/L) & plasma & -0.30 & -0.24 & $-0.45^{*}$ & -0.02 & 0.26 & 0.14 & 0.24 \\
\hline
\end{tabular}

Asterisk indicates statistically significant difference between comparisons

$g G T$ Y-glutamyl transferase, $C K$ creatine kinase, $s A A$ salivary alpha-amylase

Asterisk indicates statistically significant correlations (*: $P<0.05 ;{ }^{* *}: P<0.01 ;{ }^{* * *}: P<0.001$ )

abdominal disease could also indicate reduced hydration status, as it has previously been described in serum [40].

$\mathrm{P}$ in serum has been considered a marker of disease severity and likelihood of mortality in hospitalised foals [41]. Although in this study P in saliva did not correlate with $\mathrm{P}$ in plasma, it correlated in saliva with the SIRS score. Further studies should be performed in order to clarify the undergoing mechanisms of $\mathrm{P}$ in saliva.

The increases in sAA activity found in our study on diseased horses were in agreement with other studies performed on horses with acute abdominal disease [3, 16]. In addition, a low but significant correlation of sAA with SIRS status was observed in our study, as previously reported $[3,16]$. The lack of correlation with amylase in plasma confirms that, as humans, the sAA that appears in saliva is secreted by the salivary glands [23].

From all the analytes that showed differences between the horses with acute abdominal disease and the healthy ones, total proteins, $\mathrm{P}$ and sAA showed sensitivities higher than $70 \%$ at their optimal cut-off points and a specificity of $100 \%$ in detecting acute abdominal disease. Ideally, further studies in which these analytes are evaluated in other diseases should be performed, in order to evaluate their specificity not only in the case of healthy individuals but also in individuals with diseases other than acute abdominal disease.

The power analysis guaranteed adequate statistical analysis for evaluating differences between healthy and diseased horses in the confirmatory population. However, it would be of interest to make future studies in a larger population to evaluate if changes in analytes could be related with outcome (survivors vs. non-survivors), diagnosis (ischaemic/strangulating vs. non-ischaemic/ non-strangulating) and treatment needed (medical treatment vs. surgery). In addition, it would have been interesting to include an analysis of electrolytes in saliva in this study, which was not possible due to volume constraints.

\section{Conclusions}

A panel of 23 analytes can be measured in saliva in horses, and from these analytes, gGT, CK, urea, total bilirubin, total protein, phosphorus and sAA can be raised in horses with acute abdominal disease. Further studies should be made to evaluate and refine the possible application of these analytes in clinical situations.

\section{Additional files}

Additional file 1: Flow chart describing horses included and excluded in the diseased populations. Description of horses included or excluded from the study in the diseased populations. (PDF $225 \mathrm{~kb}$ )

Additional file 2: Linearity under dilution in saliva of aspartate aminotransferase (AST), alkaline phosphatase (ALP), y-glutamyl transferase (gGT), lipase, lactate dehydrogenase (LDH), creatine kinase (CK), butyrilcholinesterase $(B C h E)$, adenosine deaminase $(A D A)$, creatinin, urea, uric acid, total bilirubin, cholesterol, triglycerides, glucose concentration, total proteins, albumin, lactate, phosphorus (P), calcium and total esterase (TEA). Linearity under dilution study in three pools of saliva from two specimen of saliva each. The ' $x$ ' expressed activity or concentration measured and ' $y$ ' expected level at the particular dilution. $R^{2}=$ coefficient of determination of linear correlation. (PDF 2190 kb) 


\section{Abbreviations}

ADA: Adenosine deaminase; ALP: Alkaline phosphatase; ALT: Alanine aminotransferase; AST: Aspartate aminotransferase; BChE: Butyrilcholinesterase; ChE: Cholinesterase; Cl: Confidence interval; CK: Creatine kinase; CV: Coefficient of variation; gGT: Y-glutamyl transferase; Hp: Haptoblobin; HR: Heart rate; IQR: Interquartile ranges; LCR: Low-complexity region; LDH: Lactate dehydrogenase; P: Phosphorus; ROC: Receiver operator characteristic; RR: Respiratory rate; sAA: Salivary apha-amylase; SAA: Serum amyloid A: SIRS: Systemic inflammatory response syndrome; TEA: Total esterase activity; WBC: White blood cells

\section{Acknowledgements}

The authors gratefully acknowledge the intern veterinarians from the Veterinary Teaching Hospital of the University of Extremadura for collecting saliva samples. We wish to thank Juan Jesús Carreño Martínez for offering their horses for the healthy population and to Costel Ursache for helping in samples collection. D. Escribano was granted by the postdoctoral program 'Juan de la Cierva' of the 'Ministerio de Economía y Competitividad', Spain. M. Contreras-Aguilar was granted by the predoctoral contract 'FPU' of University of Murcia (R-605/2016), Spain. Funding was additionally provided by the FCT - Portuguese Science Foundation: research contract IF/01778/ 2013 (E. Lamy) and by the Seneca Foundation of Murcia Regional Government, Spain (grant number 19894/GERM/15).

\section{Authors' contributions}

MDCA and JJC conceived and designed the study. MDCA and MMC collected the data. MDCA were involved in the chemical analysis. MDCA, DE, SMS, MMC, EL, FT and JJC were involved in the data interpretation. MDCA drafted the manuscript and DE, SMS, MMC, EL, FT and JJC critically read and edited the manuscript. All authors read and approved the final manuscript.

\section{Funding}

Seneca Foundation of Murcia Region (grant number: 19894/GERM/15). Funding was additionally provided by the FCT - Portuguese Science Foundation: research contract IF/01778/2013 - E. Lamy. The funding agencies had no role in study design, data collection and analysis, decision to publish, or preparation of the manuscript.

\section{Availability of data and materials}

The datasets generated and/or analysed during the current study are not publicly available due to legal reasons but are available from the corresponding author on reasonable request.

\section{Ethics approval}

All procedures involving animals were in accordance with the ethical standards of the Bioethical Commission of Murcia University (CEEA 288/ 2017). Written owner's consent was obtained for all horses participating in this study.

\section{Consent for publication}

Not applicable.

\section{Competing interests}

None of the authors has any financial or personal relationships that could inappropriately influence or bias the content of the paper. Silvia MartínezSubiela, Elsa Lamy and Jose Joaquín Cerón are editorial board members of BMC Veterinary Research.

\section{Author details}

${ }^{1}$ Interdisciplinary Laboratory of Clinical Analysis (Interlab-UMU), Veterinary School, Campus of Excellence Mare Nostrum, University of Murcia, Campus de Espinardo s/n, 30100 Espinardo, Murcia, Spain. ${ }^{2}$ Department of Food and Animal Science, School of Veterinary Medicine, University of Barcelona, Bellaterra, 08193 Barcelona, Spain. ${ }^{3}$ Animal Medicine, Faculty of Veterinary Medicine of Cáceres, University of Extremadura, Av. de la Universidad S-N 10005 Cáceres, Spain. ${ }^{4}$ Institute of Mediterranean Agricultural and Environmental Sciences, University of Évora, Núcleo da Mitra, Apartado 94, 7006-554 Évora, Portugal.
Received: 9 February 2019 Accepted: 23 May 2019

Published online: 06 June 2019

\section{References}

1. Lindner A, Marx S, Kissenbeck S, Mosen H. Saliva collection and relationship between lactate concentration in blood and saliva of exercising horses. J Equine Vet Sci. 2000;20:52-4.

2. Bilancio G, Cavallo P, Lombardi C, Guarino E, Cozza V, Giordano F, et al. Salivary levels of phosphorus and urea as indices of their plasma levels in nephropathic patients. J Clin Lab Anal. 2018;32:1-6.

3. Contreras-Aguilar MD, Escribano D, Martín-cuervo M, Tecles F, Cerón JJ. Salivary alpha-amylase activity and cortisol in horses with acute abdominal disease : a pilot study. BMC Vet Res. 2018;14:1-7.

4. Tecles F, Rubio CP, Contreras-Aguilar MD, Lopez-Arjona M, Martinez-Miro S, Martinez-Subiela S, et al. Adenosine deaminase activity in pig saliva: analytical validation of two spectrophotometric assays. J Vet Diagn Investig. 2018:30:175-9.

5. Tecles F, Contreras-Aguilar MD, Martínez-Miró S, Tvarijonaviciute A, MartínezSubiela S, Escribano D, et al. Total esterase measurement in saliva of pigs: validation of an automated assay, characterization and changes in stress and disease conditions. Res Vet Sci. 2017;114:170-6.

6. Tecles F, Escribano D, Martínez-Miró S, Hernández F, Contreras MD, Cerón JJ. Cholinesterase in porcine saliva: analytical characterization and behavior after experimental stress. Res Vet Sci. 2016;106:23-8.

7. Barranco T, Tvarijonaviciute A, Tecles F, Carrillo JM, Sanchez-Resalt C, Jimenez-Reyes $\mathrm{P}$, et al. Changes in creatine kinase, lactate dehydrogenase and aspartate aminotransferase in saliva samples after an intense exercise: a pilot study. J Sports Med Phys Fit. 2018;58:910-6.

8. Contreras-Aguilar MD, Escribano D, Quiles A, López-Arjona M, Cerón JJ, Martínez-Subiela S, et al. Evaluation of new biomarkers of stress in saliva of sheep. Animal. 2018:1-9.

9. Greabu M, Battino M, Mohora M, Totan A, Didilescu A, Spinu T. Saliva - a diagnostic window to the body, both in health and in disease. J Med Life. 2009;2:124-32.

10. Granger DA, Kivlighan KT, El-Sheikh M, Gordis EB, Stroud LR. Salivary alphaamylase in biobehavioral research - recent developments and applications. Ann NY AcadSci. 2007;1098:122-44.

11. Nater UM, Rohleder N. Salivary alpha-amylase as a non-invasive biomarker for the sympathetic nervous system: current state of research Psychoneuroendocrinology. 2009;34:486-96.

12. Giri U, Nagaraj V, Sankaran A, Ramesh R, Rajaram S, Muthanandam S, et al. Sialochemical profile in depressive individuals under antidepressant therapy: an observational study. J Clin Diagn Res. 2018;12:VC06-9.

13. Miller BE, Deutsch O, Redlich M, Konttinen YT, Benoliel R, Zaks B, et al. Sialochemistry and cortisol levels in patients with Sjogren's syndrome. Oral Dis. 2012; 18:255-9.

14. Jacobsen S, Top Adler DM, Bundgaard L, Sørensen MA, Andersen PH, Bendixen $\mathrm{E}$. The use of liquid chromatography tandem mass spectrometry to detect proteins in saliva from horses with and without systemic inflammation. Vet J. 2014;202:483-8.

15. de Grauw JC, van Loon JPAM. Systematic pain assessment in horses. Vet J. 2016:209:14-22.

16. Contreras-Aguilar MD, Martínez-Subiela S, Cerón JJ, Martín-Cuervo M, Tecles F, Escribano D. Salivary alpha-amylase activity and concentration in horses with acute abdominal disease: association with outcome. Equine Vet J Epub. 2019.

17. Tecles F, Cerón JJ. Determination of whole blood cholinesterase in different animal species using specific substrates. Res Vet Sci. 2001;70:233-8.

18. Escribano D, Fuentes-Rubio M, Ceron JJ. Validation of an automated chemiluminescent immunoassay for salivary cortisol measurements in pigs. J Vet Diagn Investig. 2012;24:918-23.

19. Jacobsen S, Kjelgaard-Hansen M, Hagbard Petersen H, Jensen AL. Evaluation of a commercially available human serum amyloid A (SAA) turbidometric immunoassay for determination of equine SAA concentrations. Vet J. 2006; 172:315-9.

20. Christensen M, Jacobsen S, Ichiyanagi T, Kjelgaard-Hansen M. Evaluation of an automated assay based on monoclonal anti-human serum amyloid $\mathrm{A}$ (SAA) antibodies for measurement of canine, feline, and equine SAA. Vet J. 2012;194:332-7.

21. Wiedmeyer CE, Solter PF. Validation of human haptoglobin immunoturbidimetric assay for detection of haptoglobin in equine and canine serum and plasma. Vet Clin Path. 1996;25:141-6. 
22. Roy M, Kwong GPS, Lambert J, Massie S, Lockhart S. Prognostic value and development of a scoring system in horses with systemic inflammatory response syndrome. J Vet Intern Med. 2017;31:582-92.

23. Rohleder N, Nater UM. Determinants of salivary a-amylase in humans and methodological considerations. Psychoneuroendocrinology. 2009;34:469-85.

24. Faul F, Erdfelder E, Lang A, Buchner A. G* power: a flexible statistical power analysis program for the social, behavioral, and biomedical sciences. Behav Res Methods. 2007;39:175-91.

25. Hinkle DE, Wiersma W, Jurs SG. Applied statistics for the behavioral sciences. 5th ed. London: Boston Mass: Houghton Mifflin; 2003.

26. Chen G, Pramanik BN. Application of LC/MS to proteomics studies: current status and future prospects. Drug Discov Today. 2009;14:465-71.

27. Lamy E, Mau M. Saliva proteomics as an emerging, non-invasive tool to study livestock physiology, nutrition and diseases. J Proteome. 2012;75: 4251-8.

28. Dubois E, Fertin M, Burdese J, Amouyel P, Bauters C, Pinet F. Cardiovascular proteomics: translational studies to develop novel biomarkers in heart failure and left ventricular remodeling. Proteom Clin Appl. 2011;5:57-66.

29. Bossuyt PM, Reitsma JB, Bruns DE, C a G, Glasziou PP, Irwig LM, et al. The STARD statement for reporting studies of diagnostic accuracy: explanation and elaboration. Ann Intern Med. 2003;138:1-12.

30. Whitfield JB. Gamma glutamyl transferase. Crit Rev Clin Lab Sci. 2001;38: 263-355.

31. Kamath PS, Wiesner RH, Malinchoc M, Kremers W, Therneau TM, Kosberg CL, et al. A model to predict survival in patients with end-stage liver disease. Hepatology. 2001:33:464-70.

32. Gardner RB, Nydam DV, Mohammed HO, Ducharme NG, Divers TJ. Serum gamma glutamyl transferase activity in horses with right or left dorsal displacements of the large colon. J Vet Intern Med. 2005;19:761-4.

33. Lefebvre HP, Laroute V, Braun JP, Lassourd V, Toutain PL. Non-invasive and quantitative evaluation of post-injection muscle damage by pharmacokinetic analysis of creatine kinase release. Vet Res. 1996;27:343-61.

34. Tvarijonaviciute A, Barranco T, Rubio M, Carrillo JM, Martinez-Subiela S, Tecles F, et al. Measurement of Creatine kinase and aspartate aminotransferase in saliva of dogs: a pilot study. BMC Vet Res. 2017:13:168

35. Grosche A, Schroedl W, Schusser GF. Specific parameters of blood and peritoneal fluid to indicate the severity of intestinal ischemia in colic horses. Tieraerztliche Praxis Ausgabe Grosstiere Nutztiere. 2006;34:387-96.

36. Krueger CR, Ruple-Czerniak A, Hackett ES. Evaluation of plasma muscle enzyme activity as an indicator of lesion characteristics and prognosis in horses undergoing celiotomy for acute gastrointestinal pain. BMC Vet Res. 2014;10:1-7.

37. Morgan DB, Carver ME, Payne RB. Plasma creatinine and urea - creatinine ratio in patients with raised plasma urea. BMJ-British Med J. 1977:2:929-32

38. Ernst AA, Haynes ML, Nick TG, Weiss SJ. Usefulness of the blood urea nitrogen/creatinine ratio in gastrointestinal bleeding. Am J Emerg Med. 1999;17:70-2.

39. Tvarijonaviciute A, Pardo-Marin L, Tecles F, Carrillo JD, Garcia-Martinez JD, Bernal $L$, et al. Measurement of urea and creatinine in saliva of dogs: a pilot study. BMC Vet Res. 2018:14:1-6.

40. Muñoz A, Riber C, Trigo P, Castejón-Riber C, Castejón FM. Dehydration, electrolyte imbalances and renin-angiotensin-aldosterone-vasopressin axis in successful and unsuccessful endurance horses. Equine Vet J. 2010;42:83-90.

41. Kamr AM, Dembek KA, Hildreth BE, Morresey PR, Rathgeber RA, Burns TA, et al. The FGF-23/klotho axis and its relationship with phosphorus, calcium, vitamin D, PTH, aldosterone, severity of disease, and outcome in hospitalised foals. Equine Vet J. 2018:50:739-46.

\section{Publisher's Note}

Springer Nature remains neutral with regard to jurisdictional claims in published maps and institutional affiliations.

Ready to submit your research? Choose BMC and benefit from:

- fast, convenient online submission

- thorough peer review by experienced researchers in your field

- rapid publication on acceptance

- support for research data, including large and complex data types

- gold Open Access which fosters wider collaboration and increased citations

- maximum visibility for your research: over $100 \mathrm{M}$ website views per year

At $\mathrm{BMC}$, research is always in progress.

Learn more biomedcentral.com/submissions 